\title{
VENTRICULAR TACHYCARDIA AND FIBRILLATION WITH IMPLANTED ELECTRICAL PACEMAKERS
}

\author{
BY \\ JAMES S. ROBINSON*, GRAEME SLOMAN, JOHN HOGAN, AND IAN H. MCCONCHIE \\ From Royal Melbourne Hospital, Victoria, Australia
}

Received April 12, 1965

The treatment for patients with Stokes-Adams attacks complicating complete heart block now includes implantation of electrical pacemakers (Elmqvist and Senning, 1960; Glenn et al., 1959; Simpson et al., 1962). With increasing clinical experience, complications of this form of treatment are becoming more apparent. These include component failure with resultant inadequate stimulation (Chardack, Gage, and Greatbatch, 1961 ; Zoll et al., 1961 ; Elmqvist et al., 1963), or ventricular tachycardia and fibrillation with normal pacemaker function (Elmqvist et al., 1963; Portal et al., 1962; Dressler, 1964; A. Leatham and J. G. Davies, 1964, personal communication). Dressler (1964) reviewed ventricular arrhythmias in patients with normally functioning pacemakers and considered that a slow rate of stimulation was the underlying cause of these arrhythmias.

We report 3 patients with recurrent ventricular tachycardia and fibrillation in the presence of normal pacemaker function.

\section{CASE REPORTS}

Case 1. A 68-year-old diabetic woman with complete heart block and Stokes-Adams attacks was treated by implantation of a pacemaker†. Following this she was well for 10 months, at which time the stimulus rate had increased from the original of 60 a minute to 120 a minute. This rise in rate indicated a failing pacemaker, and a new unit at the rate of 70 a minute was implanted.

Following operation recurrent episodes of ventricular fibrillation occurred and despite drug therapy and resuscitative measures death occurred in ventricular fibrillation, 36 hours after operation. Investigation of the pacemaker revealed normal function.

Case 2. A 69-year-old man had Stokes-Adams attacks complicating complete heart block. After implantation of a pacemaker at a rate of 63 a minute attacks were controlled. He remained well for one year, and then Stokes-Adams attacks recurred. The pacemaker rate was found to have fallen to 24; a component failure had occurred. An attack observed in hospital was due to ventricular fibrillation.

A second pacemaker with a rate of discharge of 70 a minute was implanted. Immediately after operation a 30-second episode of ventricular tachycardia fibrillation occurred, with spontaneous reversion to sinus rhythm. In the course of the next three days there were recurrent episodes of ventricular tachycardia fibrillation (Fig. 1). Attacks were not controlled by the use of procaine amide, quinidine, digoxin, or propranolol (Inderal).

As medical treatment failed and with the previous experience (Case 1), the abdominal wound was reopened and the electrodes detached from the pacemaker unit, to exclude the possibility that the pacemaker stimulus was responsible for initiating these ventricular arrhythmias. Without stimulation complete heart block persisted and ventricular fibrillation followed (Fig. 2). Stimulation was applied to the myocardial

* In receipt of Grant-in-Aid G.162 from the National Heart Foundation of Australia.

$\dagger$ In all three patients St. George's Pacemakers were used. 


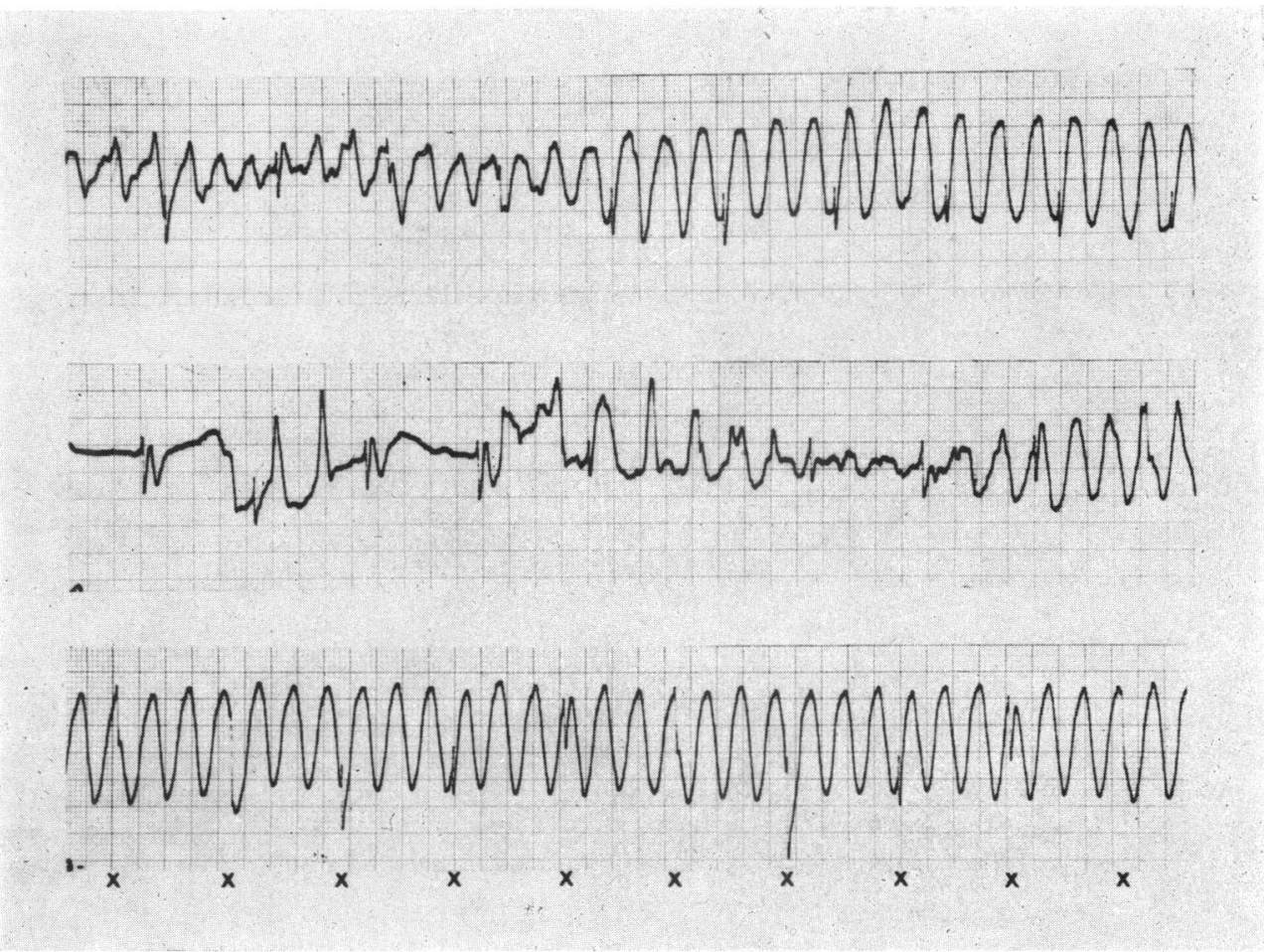

Fig. 1.-Case 2. An episode of ventricular tachycardia fibrillation. Pacemaking stimulus is indicated by $\mathrm{X}$.

electrodes by an external pacemaker set at a rate of 60 a minute; nevertheless there was recurrent ventricular fibrillation (Fig. 2). Resuscitation was unsuccessful and death occurred.

Case 3. A 68-year-old diabetic woman with complete heart block developed Stokes-Adams attacks due to ventricular tachycardia fibrillation. A pacemaker with a rate of 65 a minute was implanted. This controlled the attacks, though ventricular extrasystoles were detected. The patient was well for four months when once again episodes of dizziness recurred. The rate of discharge of the pacemaker was 60 a minute, and function was assessed as normal (Knuckey, McDonald, and Sloman, 1965). Attacks of dizziness were found to be due to episodes of ventricular fibrillation (Fig. 3).

A bipolar electrode catheter was passed to the right ventricle, and internal stimulation was applied at a rate of 70 a minute. In addition, the previously implanted pacemaker was allowed to continue to function. With these two sources of cardiac stimulation the heart rate was increased, varying between 90 and 110 a minute.

With this form of treatment there were no further bouts of ventricular tachycardia fibrillation. At an elective operation three days later the implanted pacemaker was disconnected and replaced by a new internal pacemaker unit. The electrode catheter was then removed. With a heart rate of 77 a minute the patient has been well and there have been no further episodes of ventricular tachycardia or fibrillation.

\section{Discussion}

Fatal ventricular fibrillation in patients with implanted pacemakers has been reported (Portal et al., 1962; Elmqvist et al., 1963; Dressler, 1964). In 3 patients with implanted pacemakers and ventricular arrhythmias, Dressler (1964) found that increasing the rate of electrical stimulation up to 96 a minute suppressed the arrhythmia in 2 patients, while one died with persistent ventricular fibrillation. He concluded that electrical pacemakers should have a stimulating rate of 90 a minute, 


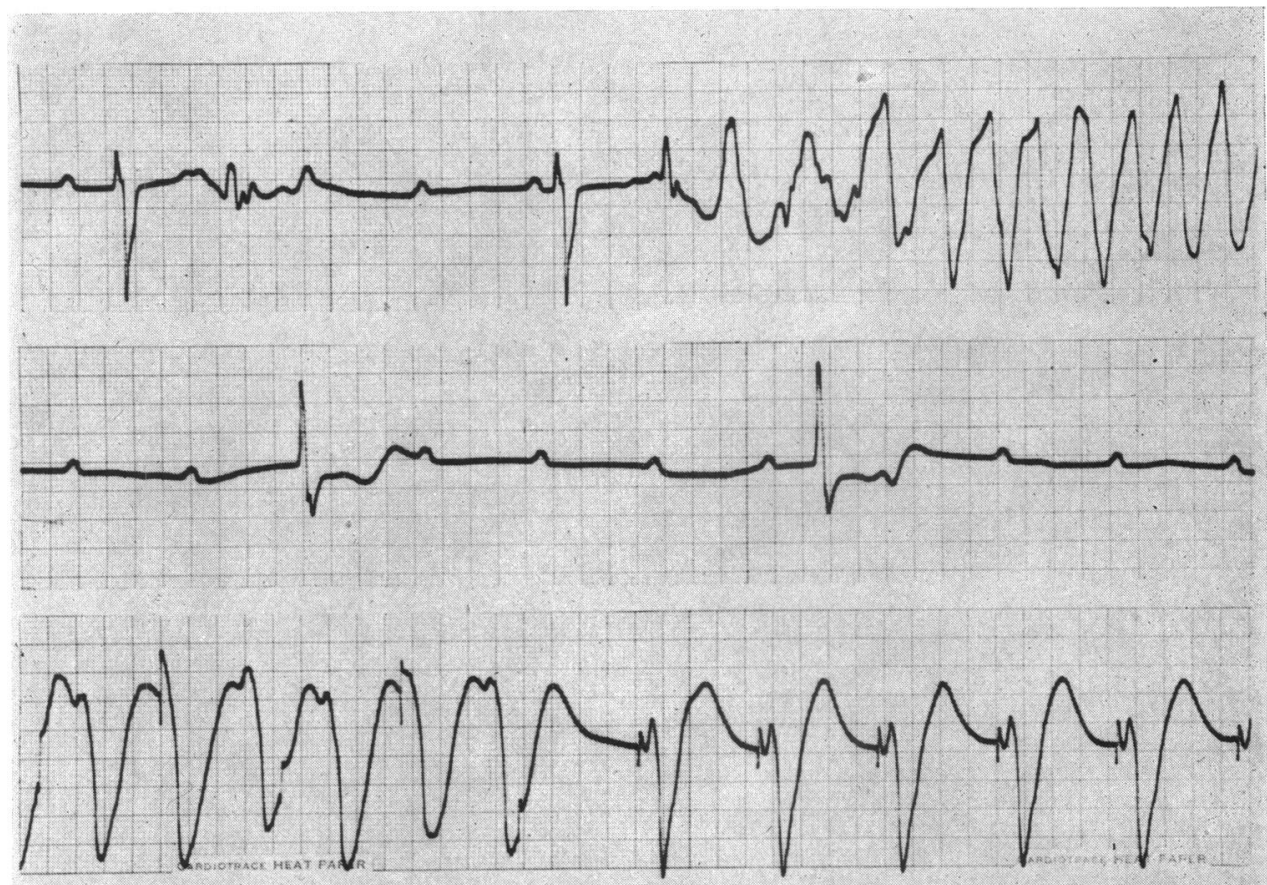

Fig. 2.-Case 2. Complete heart block when pacemaker detached, and an episode of ventricular tachycardia fibrillation. Lower strip illustrates ventricular tachycardia when external pacemaking with myocardial electrodes was commenced.

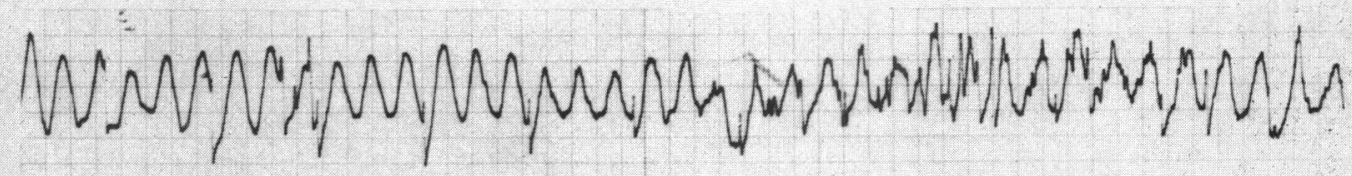

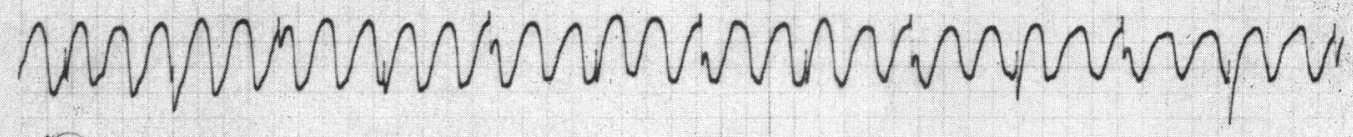

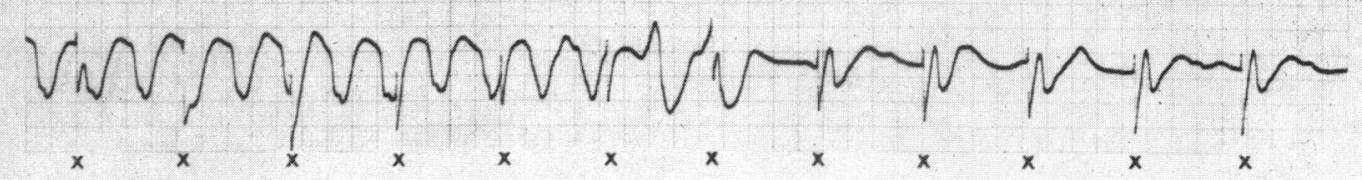

FIG. 3.-Case 3. An episode of ventricular tachycardia fibrillation, with spontaneous return to normal pacing. Pacemaker stimulus indicated by $\mathrm{X}$. 


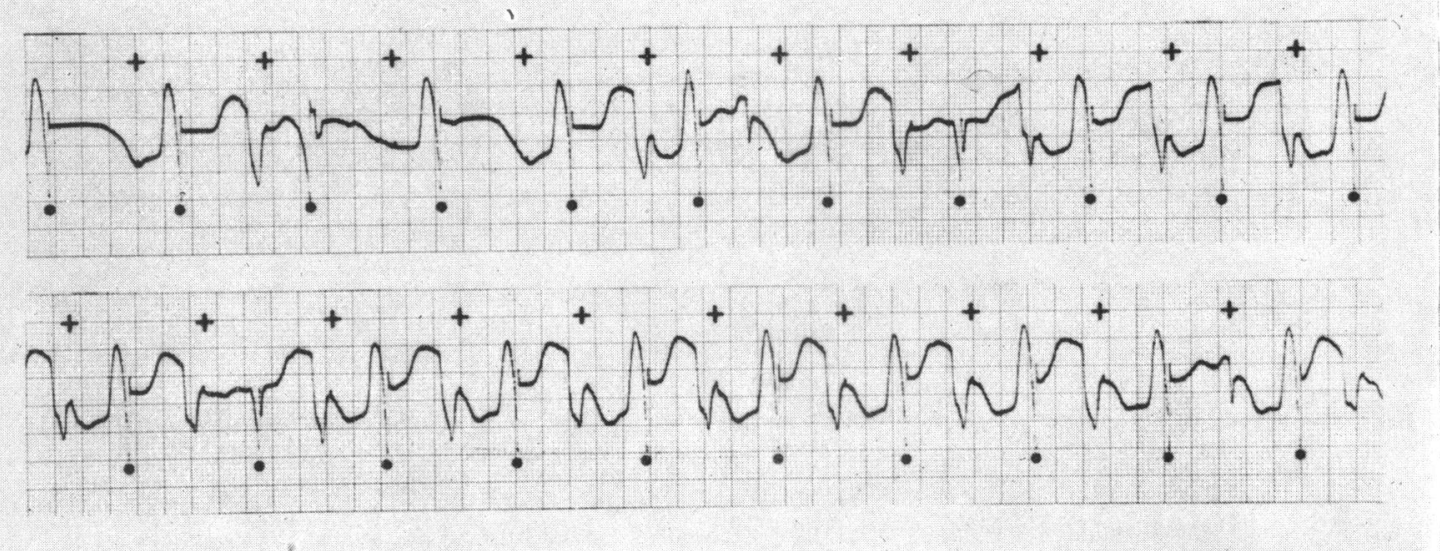

Fig. 4.-Case 3. Combined stimulation from implanted pacemaker $(\bullet)$, and a bipolar electrode catheter in the right ventricle $(+)$.

with facility for increasing to 120 a minute, in order to allow control of ventricular arrhythmias occurring at lower rates of pacing.

In our 3 patients ventricular tachycardia fibrillation occurred, and in 2 it was ultimately fatal. In Case 1, the sudden change in the stimulus rate of 120 to 60 a minute may have been responsible for induction of ventricular fibrillation. There had been no Stokes-Adams attacks at the higher rates of pacing. In Case 2, Stokes-Adams attacks were not controlled by a pacemaker rate of 70 a minute. This pacemaker was shown not to be responsible for the induction of ventricular fibrillation. Unfortunately the response to an increase in stimulation rate was not explored. In the remaining patient (Case 3), increase in stimulation rate was effective in controlling ventricular tachycardia fibrillation.

Slow rates of electrical pacing prolong the effective life of a pacemaker. However, it appears that slow rates of electrical stimulation may lead to ventricular arrhythmias in some patients (Dressler, 1964; A. Leatham, and J. G. Davies, 1964, personal communication).

When the pacemaker has a fixed rate of discharge, an increase in ventricular rate can be achieved by insertion of a catheter electrode connected to an external pacemaker. The response to combined stimulation is a variable but increased ventricular rate (Fig. 4), the resultant rate being dependent upon the individual rates of stimulation and the time relation of discharge to the refractory period of the ventricle. This catheter electrode technique as a temporary measure controls the ventricular rate and permits appropriate pacemaker replacement as an elective procedure.

\section{SUMMARY}

Three patients with normally functioning implanted pacemakers who developed ventricular tachycardia fibrillation are reported. It is suggested that by increasing the rate of pacemaker stimulation ventricular arrhythmias may be suppressed. An emergency method for control of ventricular arrhythmias in such patients is outlined.

\section{REFERENCES}

Chardack, W. M., Gage, A. A., and Greatbatch, W. (1961). Correction of complete heart block by a self-contained and subcutaneously implanted pacemaker. J. thorac. Surg., 42, 814.

Dressler, W. (1964). Observations in patients with implanted pacemaker. 111. Frequency of ventricular tachycardia as cause of Adams-Stokes attacks and rate of pacing required for its prevention. Amer. Heart J., 68, 19. 
Elmqvist, R., Landegren, J., Pettersson, S. A., Senning, Å., and William-Olsson, G. (1963). Artificial pacemaker for treatment of Adams-Stokes syndrome and slow heart rate. Amer. Heart J., 65, 731 .

- , and Senning, A. (1960). An implantable pacemaker for the heart. In Medical Electronics: Proceedings of the 2nd International Conference, Paris, 1959, ed. C. N. Smyth, p. 253. Iliffe, London.

Glenn, W. W. L., Mauro, A., Longo, E., Lavietes, P. H., and Mackay, F. J. (1959). Remote stimulation of the heart by radiofrequency transmission; Clinical application to a patient with Stokes-Adams syndrome. New Engl. J. Med., 261, 948.

Knuckey, L., McDonald, R., and Sloman, G. (1965). A method of testing implanted cardiac pacemakers. Brit. Heart J., 27, 483.

Portal, R. W., Davies, J. G., Leatham, A., and Siddons, A. H. M. (1962). Artificial pacing for heart-block. Lancet, 2, 1369.

Simpson, J. A., Gibson, P., Stanford, R. W., and McLernon, D. B. (1962). Prolonged cardiac pacemaking in StokesAdams disease. Lancet, 2, 226.

Zoll, P. M., Frank, H. A., Zarsky, L. R. N., Linenthal, A. J., and Belgard, A. H. (1961). Long-term electric stimulation of the heart for Stokes-Adams disease. Ann. Surg., 154, 330. 